\title{
Comments to "Long-Term Survival Benefit and Potential for Cure After R1 Resection for Colorectal Liver Metastases"
}

\author{
Alessandro Cucchetti, MD, Matteo Cescon, MD, PhD, Valentina Bertuzzo, MD, and Giorgio Ercolani, MD, PhD \\ Department of Medical and Surgical Sciences - DIMEC, S.Orsola - Malpighi Hospital, Alma Mater Studiorum - \\ University of Bologna, Bologna, Italy
}

\section{TO THE EDITORS}

We read with interest the article by Hosokawa et al. regarding what they called as "potentially cured" patients submitted to R1 resection of colorectal liver metastases (CLM). ${ }^{1}$ Authors defined "cure" as a disease-free interval of 5 years or more after the last hepatectomy or the last resection of extra-hepatic metastases. From an initial study population of 428 resected patients (R0: 219; R1: 209), they excluded $36.7 \%$ of patients with less than 5 years of follow-up and identified 271 patients for survival analyses (R0: 130; R1: 141). In this latter study group, $18 \%$ of initially R1 and $23 \%$ of R0 patients did not experience any further tumor recurrence. We believe that this measure can not be considered as a true "cure fraction". In epidemiology, cure is said to occur when the mortality of patients, treated for a specific disease, returns to the same level as that of the general population, as endorsed by the United States National Cancer Institute. ${ }^{2}$ In the present analysis such a comparator was not provided and Authors empirically set the time-to-cure at 5 years from surgery. We recently reported what is the probability of being cured from CLM after R0 hepatic resection using a cure-rate model. ${ }^{3}$ We observed that in the whole study population (1012 patients) the time-to-cure was 6.5 years with a $99 \%$ level of confidence, meaning that after this time point, a patient alive without tumor recurrence could be considered cured with $99 \%$ certainty. The time-to-cure was found to increase up to more than 7 years in presence of negative prognostic factors. Thus, from this point of view the

(C) Society of Surgical Oncology 2017

First Received: 15 February 2016;

Published Online: 16 October 2017

A. Cucchetti, MD

e-mail: aleqko@libero.it threshold of 5 year has to be considered too early in respect to the history of the cancer. If not statistically assessed, the "safety" threshold to define "cure" must be moved toward, even up to 10 years, as already adopted by other Authors., In the view of all these aspects, the present definition of "cure" seems misleading and can lead to inaccurate informations to patients who would like to be fully informed regarding what awaits them after hepatic surgery. ${ }^{3}$ On the contrary, we believe that the measure that Authors provided in their article has to be considered as a "conditional survival" that is, in the present study, the probability of being alive without tumor recurrence once that 5 years from after the last hepatectomy or the last resection of extra-hepatic metastases have already passed. ${ }^{6,7}$

\section{REFERENCES}

1. Hosokawa I, Allard MA, Gelli M, et al. Long-term survival benefit and potential for cure after R1 resection for colorectal liver metastases. Ann Surg Oncol. 2016;23:1897-905

2. Statistical Methodology and Applications Branch, Data Modeling Branch, National Cancer Institute. Cansurv, version 1.1. http:// surveillance.cancer.gov/cansurv/index.html. Accessed 1 Feb 2014.

3. Cucchetti A, Ferrero A, Cescon M, et al. Cure model survival analysis after hepatic resection for colorectal liver metastases. Ann Surg Oncol. 2015;22:1908-14.

4. Tomlinson JS, Jarnagin WR, DeMatteo RP, et al. Actual 10-year survival after resection of colorectal liver metastases defines cure. J Clin Oncol. 2007;25:4575-80.

5. Pulitanò C, Castillo F, Aldrighetti L, et al. What defines "cure" after liver resection for colorectal metastases? Results after 10 years of follow-up. HPB (Oxford). 2010;12:244-9.

6. Tan MC, Butte JM, Gonen M, et al. Prognostic significance of early recurrence: a conditional survival analysis in patients with resected colorectal liver metastasis. HPB (Oxford). 2013;15(10):803-13.

7. Hieke S, Kleber M, König C, Engelhardt M, Schumacher M. Conditional survival: a useful concept to provide information on how prognosis evolves over time. Clin Cancer Res. 2015;21:1530-6. 